Isolation, identification and characterization of Microcystin degrading bacteria for water treatment solution

By

Fathima Sumaiya Idroos

A thesis submitted in fulfillment for the award of the degree of Doctor of Philosophy in Zoology

University of Sri Jayewardenapura

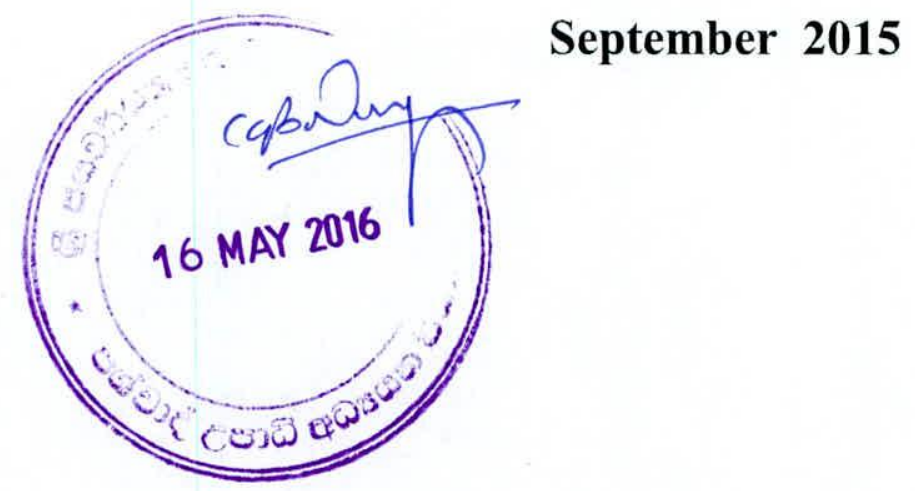




\section{CERTIFICATION OF SUPERVISORS}

"We certify that the candidate has incorporated all corrections, additions and amendments recommended by the examiners to this final version of the $\mathrm{PhD}$ thesis".

Supervisor:

Prof. Pathmalal Manage

Professor of Zoology,

Department of Zoology,

Faculty of Applied Sciences, University of Sri Jayewardenepura.

$16 / 05 / .05 / 16 \ldots$

Co-Supervisor:

Prof. B.G.D.N.K. De Silva

Professor of Zoology,

Department of Zoology,

Faculty of Applied Sciences, University of Sri Jayewardenepura.

\begin{tabular}{l|l|l}
16 & 05 & 2016 \\
$\ldots 1.16$ & &
\end{tabular}

Date

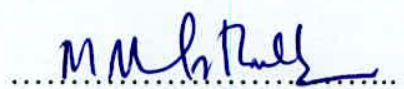

Prosignattitimalal M. is.

Head / Department of $Z \mathrm{~m}$ ?

University of Sri Jayewariet:

Nugegoda

Sri Lanka.

Tel: 0112-804515

Co-Supervisor:

Dr.S.D.M. Chinthaka

Senior lecturer

Department of Chemistry,

Faculty of Applied Sciences, University of Sri Jayewardenepura.

\section{6) $05.5 \cdot 2016 \ldots$}

Date

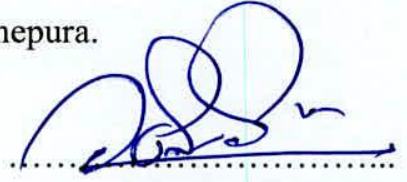

Signature 


\section{DECLARATION OF STUDENT}

I declare that the work presented in this thesis is my own, except where otherwise acknowledged, and has not been submitted in any form for another degree or qualification at any other academic institution. The work described in this thesis was carried out under the supervision of Prof.M.M.Pathmalal as the chief investigator while Prof.B.G.D.N.K. De Silva and Dr. S.D.M. Chinthaka were the co- supervisors.

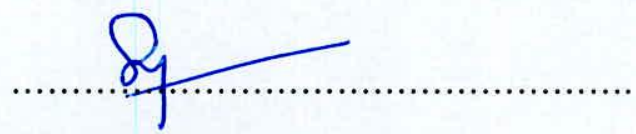

\section{F. Sumaiya Idroos}

Department of Zoology

University of Sri Jayewardenepura

Sri Lanka 


\section{DECLARATION OF SUPERVISOR}

I certify that the above declaration made by the candidate is true and that the work presented in this thesis was undertaken with my supervision. Furthermore, thesis writing was also guided by me.

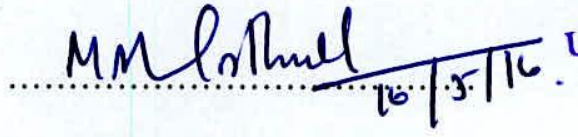

Prof. Pathmalal M. Manage / Pepartment of Zoology U Sri Jayewardenepura

\section{Prof.M.M.Pathmalal}

Nri anka.

Sri Lanka. 0

Department of Zoology

University of Sri Jayewardenepura

Sri Lanka 


\section{DECLARATION OF CO-SUPERVISOR}

I certify that the above declaration made by the candidate is true and that the work presented in this thesis was undertaken with my supervision. Furthermore, thesis writing was also guided by me.

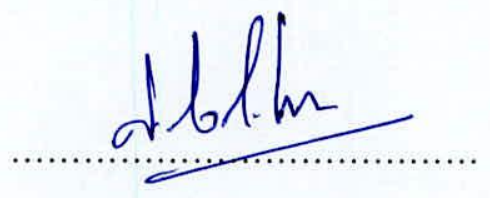

Prof. B.G.D.N.K.De Silva

Department of Zoology

University of Sri Jayewardenepura

Sri Lanka 


\section{DECLARATION OF CO-SUPERVISOR}

I certify that the above declaration made by the candidate is true and that the work presented in this thesis was undertaken with my supervision. Furthermore, thesis writing was also guided by me.

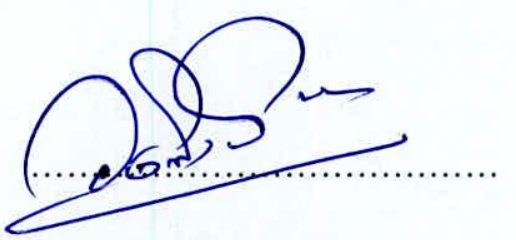

Dr. S.D.M.Chinthaka

Department of Chemistry

University of Sri Jayewardenepura

Sri Lanka 


\section{Table of Contents}

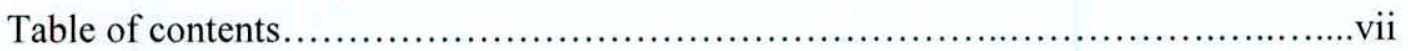

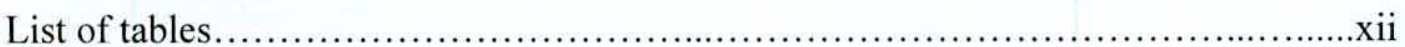

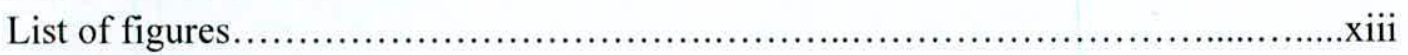

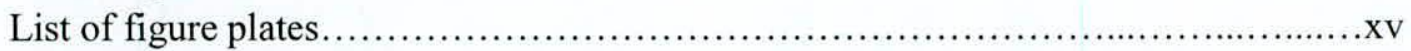

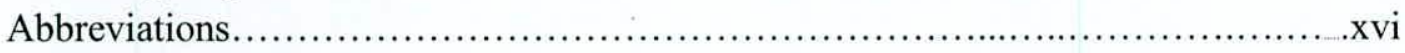

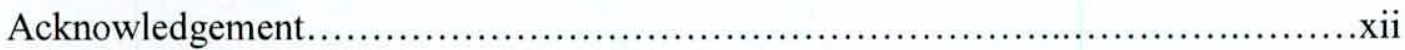

Abstract..............................................................................

CHAPTER 1 - INTRODUCTION ...................................................

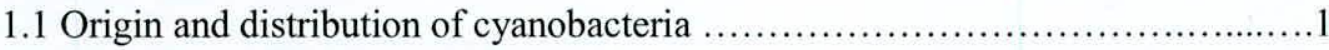

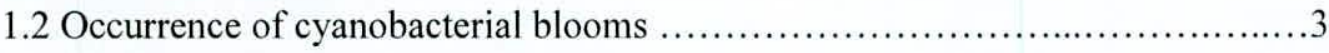

1.3 Harmful effects of cyanobacterial blooms ................................

1.3.1 Environmental and water quality issues .............................

1.3.2 Health impacts of cyanobacteria blooms ............................ 9

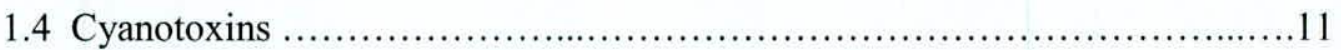

1.4.1 Cyclic peptide hepatotoxins - Microcystins (MCs) and

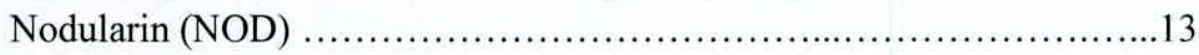

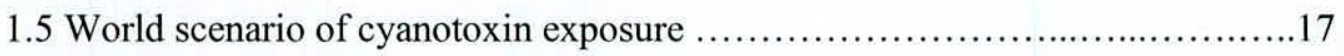

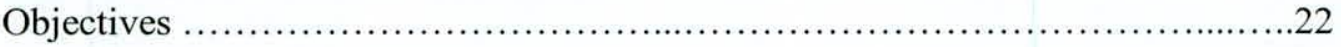

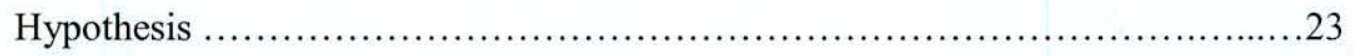

CHAPTER 2 - LITERATURE REVIEW .................................24

2.1 Occurrence of nuisance Cyanobacteria and Microcystins in reservoirs of Sri Lanka ................................................ 24

2.2 Current Treatment Technologies for Microcystins ...........................27

2.1.1 Physical removal method of Microcystins ............................27

2.1.2 Chemical treatment methods for Microcystin removal ...................29

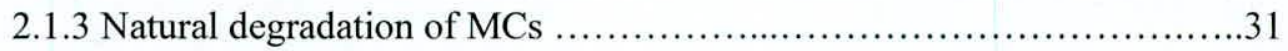




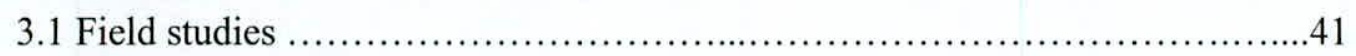

3.1.1 Study area: Reservoir and Watershed Characteristics ....................41

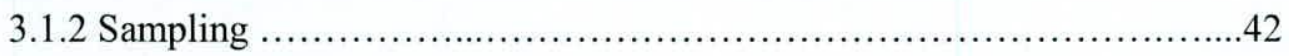

3.1.2 a Chemicals ................................................ 43

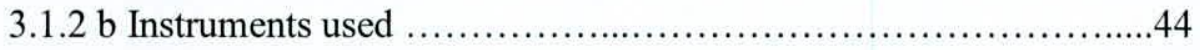

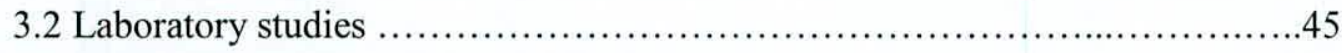

3.2.1 Measurement of chemical parameters ..............................45

3.2.2 Identification and enumeration of phytoplankton .....................46

3.2.3 Extraction and quantification of MCs ...............................46

3.2.3a Filter method ..................................................46

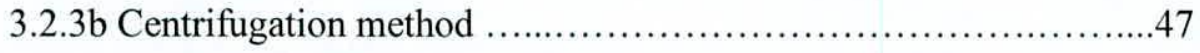

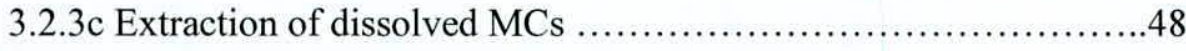

3.2.3d Quantification of MCs and development of standard plots ...........................................49

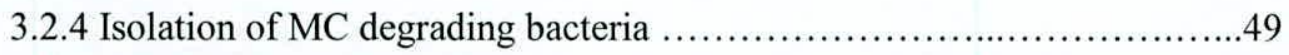

3.2.4a Enrichment studies .........................................49

3.2.4b Isolation of bacteria through enrichment studies .................50

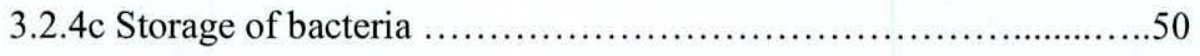

3.2.4d Regular processing and sub-culturing of bacteria ................50

3.2.5 Screening of MCs degrading bacteria ................................51

3.2.5a Preparation of bacterial inocula .............................51

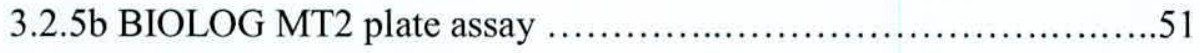

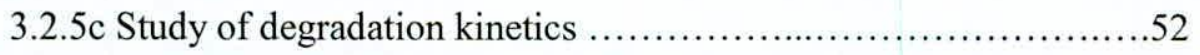

3.2.6 Tentative identification of MC-LR degraders by Biochemical tests ........53

3.2.6a Gram strain of bacteria ....................................53 


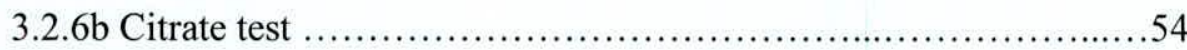

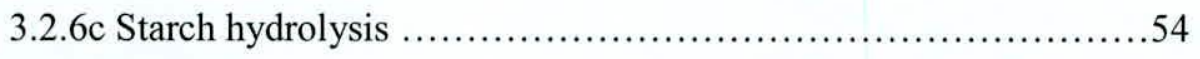

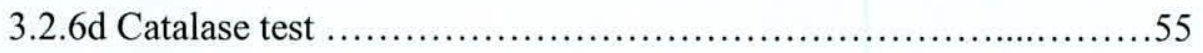

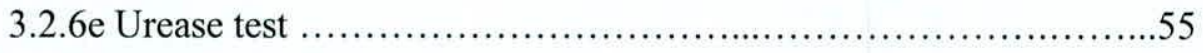

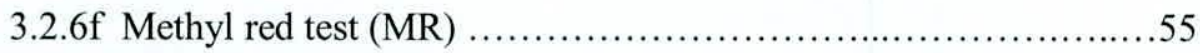

3.2.6g Vogus proskauer test (VP) .................................55

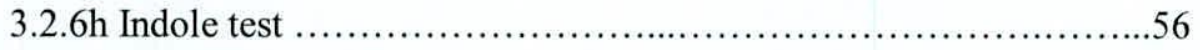

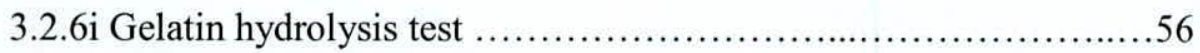

3.2.6j Lactose Fermentation test ..................................56

3.2.7 Phylogenetic Identification of bacteria ............................56

3.2.8 Optimization of bacterial degradation of MC-LR at

different temperatures, nitrates and phosphate concentrations .............57

3.2.8a Study of effect of temperature on bacterial degradation ...........57

3.2.8b Effect of phosphate and nitrate concentration on MC-LR

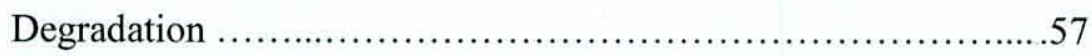

3.2.8c Degradation of a cocktail of MCs ..............................58

3.2.9 Identification of $m l r A, m l r B, m l r C$ and $m l r D$ genes .....................58

3.2.10 Establishment of laboratory scale sand filter ..........................61

3.2.10a Development of a biological layer ........................61

3.2.10b Preparation of Citric acid treated cotton ......................61

3.2.10.c Structure of the sand filter .................................62

3.2.11 Use of bacterial enzymes for the removal of MCs .....................64

3.2.12 Statistical analysis ................................................. 64

CHAPTER 4 - RESULTS AND DISCUSSION ...............................66

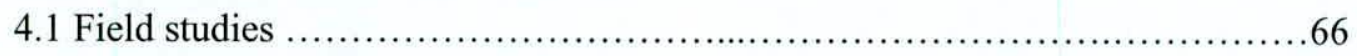

4.1.1 Physico-chemical and biological parameters ...........................66 
4.1.2 Principle component analysis (PCA) of Physico-chemical and biological parameters of sampled water bodies

4.1.3 Similarities and dissimilarities between water bodies .....................76

4.1.4 Occurrence of MC-LR and effect of physico-chemical parameters ..........77

4.1.5 Phytoplankton composition of water bodies .............................79

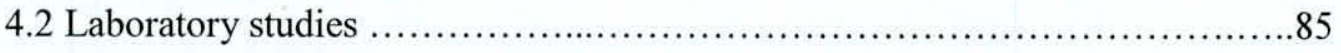

4.2.1 Extraction and quantification of MCs and NOD ...................... 85

4.2.2 Isolation of potential bacterial strains through enrichment studies ...........89

4.2.3 Screening of MC-LR degrading bacteria ..........................90

4.2.4 Study of degradation kinetics of bacteria ............................97

4.2.5 Gram stain and biochemical tests ................................ 105

4.2.6 Phylogenetic identification of bacteria strains .......................106

4.2.7 Effect of water temperature on bacterial degradation of MC-LR ........107

4.2.8 Effect of nutrients on degradation of MCs .......................... 110

4.2.9 Biodegradation of multiple MCs and NOD ..........................113

4.2.10 Presence of $m \operatorname{lr} A, m \operatorname{lr} B, m \operatorname{lr} C$ and $m \operatorname{lr} D$

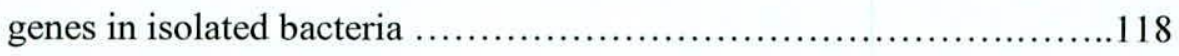

4.2.11 Development of a substrate to attach bacteria ........................120

4.2.12 Development of laboratory scale sand filter .......................124

4.2.13 Use of bacterial enzymes for the removal of MCs ......................126

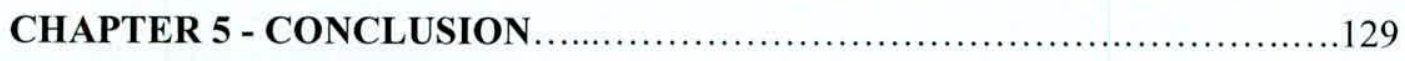

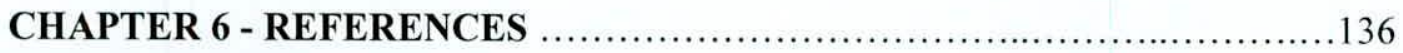

APPENDICES

Appendix 1-Publications............................................. 158

Appendix 2-Sri Lankan Water quality guidelines $2013 \ldots \ldots \ldots \ldots \ldots \ldots \ldots \ldots \ldots 1$

Appendix 3- Determination of total phosphate ............................ 165 
Appendix 4- Determination of nitrate

Appendix 5- Determination of chlorophyll a

Appendix 6-Standard plots for Microcyctins and Nodularins 172

Appendix 7 - Medium preparation for biochemical tests . 174

Appendix 8 - Turkey's test results of comparing water bodies 178 


\section{LIST OF TABLES}

Table 1.1 Alert levels for cyanobacterial blooms...............................6

Table 1.2 Frequencies of mass occurrences of toxic

cyanobacteria in freshwaters........................................10

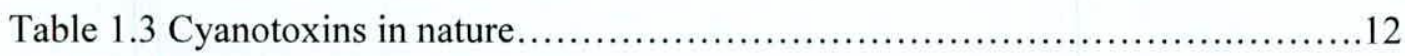

Table 1.4 Variation of amino acid on some selected MCs.............................14

Table 2.1 Microcystin contamination status of some selected water bodies in Sri Lanka..................................................

Table 2.2 Microcystin and nodularin degrading bacteria modified bacteria ...................33

Table 3.1 Types and user categories of the reservoirs subjected to present study.........42

Table 3.2 Details of instruments used for the study................................44

Table 3.3 Water quality parameters used, respective abbreviations and units and methods of analysis....................................59

Table 3.4 Forward and reverse Primer sequences used for the detection of $m l r$ gene cluster.

Table 3.5 Filter design, material and operating conditions of the sand filter column

Table 4.1 Physico-chemical parameters and Biological parameters of studied water bodies.

Table 4.2 Pearsons correlation coefficient between water quality parameters and MC-LR concentrations....

Table 4.3 Phytoplankton composition of studied water bodies........................80

Table 4.4 Number of bacterial strains isolated from each water body.....................90

Table 4.5 Half life time of isolated bacterial strains.................................... 104

Table 4.6 Gram identification of bacterial strains................................... 105

Table 4.7 Biochemical test results of bacterial strains ............................105 


\section{LIST OF FIGURES}

Figure.1.1 Harmful effects of cyanobacterial blooms.................................

Figure 1.2 Cyclic structure of Microcystin-LR .................................. 15

Figure 1.3 Cyclic structure of Nodularin.......................................... 16

Figure 2.1 Proposed MC-LR degradation pathways..................................38

Figure $2.2 \mathrm{mlr}$ gene clusters indicating the presence of $m \operatorname{lr} A, m l r B, m l r C$ and $m l r D$ genes.

Figure 3.1 Schematic diagram for the extraction of intracellular MCs

using the filter method

Figure 3.2 Schematic diagram for the extraction of intracellular MCs

using the centrifugation method.

Figure 3.3 BIOLOG MT2 plate to screen bacterial degradation of MC-LR .............52

Figure 3.4 Structure of the Sand filter..........................................63

Figure 4.1 PCA plot for physico-chemical and biological parameters of

sampled water bodies

Figure 4.2 Loading plot for physico-chemical and biological parameters

of sampled water bodies

Figure 4.3 (a) UV chromatogram at (200-300 nm), (b) UV spectrum

$238 \mathrm{~nm}$ with relative purity $>95 \%$ of MC-LR

Figure 4.4 (a) UV chromatogram at (200-300 nm), (b) UV spectrum

$238 \mathrm{~nm}$ with relative purity $>95 \%$ of of MC-LF.

Figure 4.5 (a) UV chromatogram at (200-300 nm), (b) UV spectrum

$238 \mathrm{~nm}$ with relative purity $>95 \%$ of MC-LW

Figure 4.6 (a) UV chromatogram at (200-300 nm), (b) UV spectrum

$238 \mathrm{~nm}$ with relative purity $>95 \%$ of MC-RR.

Figure 4.7 (a) UV chromatogram at (200-300 nm), (b) UV spectrum

$238 \mathrm{~nm}$ with relative purity $>95 \%$ of NOD

Figure 4.8 BIOLOG MT2 plate wells showing positive wells in purple

and negative wells colorless....

Figure 4.9 BIOLOG screen for MC-LR metabolism by 12 bacterial strains at $24 \mathrm{~h}$

of incubation with three MC-LR concentrations and controls. 
Figure 4.10a BIOLOG screen for MC-LR metabolism by 6 bacterial strains at $0,3,6,15,18,24$ and $48 \mathrm{~h}$ of incubation with three MC-LR concentrations and controls.

Figure 4.10b BIOLOG screen for MC-LR metabolism by 6 bacterial strains at $0,3,6,15,18,24$ and $48 \mathrm{~h}$ of incubation with three MC-LR concentrations and controls.

Figure 4.11 Degradation kinetics of selected bacterial strains .98

Figure 4.12 Chromatograms of MC-LR degradation by (a)12GK, (b) 4B4,1

(c) JAY and (d) 13UL strains.

Figure 4.13 Evolutionary relationships of taxa Stentrophomonas, Bacillus and Rahnella.

Figure 4.14 Degradation of MC-LR by bacterial strains at different temperatures.

Figure 4.15 Degradation of MC-LR by all four bacterial in the presence of Phosphate....

Figure 4.16 Degradation of MC-LR by all four bacterial in the presence of Nitrates

Figure 4.17 Degradation of a cocktail mixture.

Figure 4.18 PCR bands obtained for the presence of $m l r$ gene cluster in isolated bacterial strains

Figure 4.19a Optical densities of different substrates used for attachment of bacteria.

Figure 4.19b Optical densities of different substrates used for attachment of bacteria

Figure 4.20 MC-LR removal percentages through experimental and control sand filter setups.

Figure 4.21 MC-LR removal percentage by extracellular enzyme extracts.... 


\section{LIST OF FIGURE PLATES}

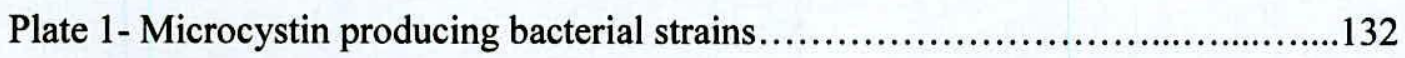

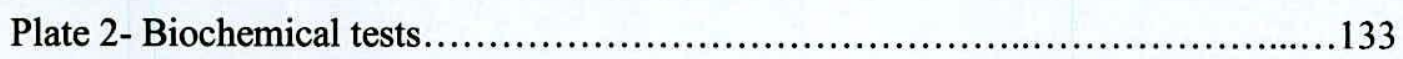

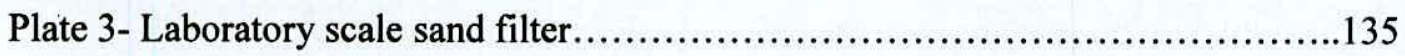




\section{ABBREVIATIONS}

Advanced Oxidation Processes

AOP

Cylindrospermopsin

CYN

deoxy-cylindrospermopsin

doCYN

Deoxy ribo nucleic acid

DNA

High Performance Liquid Chromatography

HPLC

Microcystin-LR

MC-LR

Microcystins

MCs

National water supplies and drainage board

NWSDB

Nodularins

NOD

Non-ribosomal Polypeptide

NRPS

Powdered activated carbons

PAC

Protein Phosphatases Types $1 \mathrm{~A}$

PP1

Protein Phosphatases Types 2 A

PP2

Reverse osmosis

RO

Room temperature

RT

Slow sand filtration

SSF

Total nitrogen

TN

Total phosphate

TP 


\section{ACKNOWLEDGEMENTS}

I would like to extend my heart filled gratitude to my principal investigator Prof.

Pathmalal M Manage for guiding me all the way from my bachelor's degree up to my doctorate. I also would like to thank my supervisors Prof. B.G.D.N.K De Silva and Dr. S.D.M Chinthaka for their immense support, guidance given to me throughout this project.

My heartiest gratitude to goes to all lecturers of Department of Zoology, University of Sri Jayewardenepura for creating a most supportive and friendly environment within the Department to carry out the research work.

I also extend my sincere thanks to Prof. Linda Lawton, Dr. Christine Edwards and Dr. Aakash Welagamge (Robert Gordon University, United Kingdom) for their great support provided to me during the International workshop on Cyanotoxin analysis.

I am also very grateful to Mr. Ishara Rathnayake, Senior researcher, Genetech, Sri Lanaka for guiding me to work out with sequencing studies. My thanks also go to the Industrial technology institute of Sri Lanka for helping in freeze drying of samples.

I would also like to extend a word of gratitude to the National research council of Sri Lanka, for granting me the funds in order to complete my study.

My heartiest gratitude to Mrs. Indika De Silva, Ms.Yashodara Liyanage, Mr.Yohan Mahagamage, Mr. Manoj Wijesekara and Ms. Poorna Piyathilake of Algae and water quality laboratory, University of Sri Jayewardenepura for being with me all the time in need providing the support and courage through out my research period.

I am extremely grateful to my Mum, late Dad not only for their love but for the opportunities they have given me along the way. Last but not least I am very much thankful for my loving husband for being the greatest pillar of my strength and being there for me whenever I need. 


\title{
Isolation, identification and characterization of Microcystin degrading bacteria for water treatment solution
}

\author{
Fathima Sumaiya Idroos
}

\begin{abstract}
Microcystin -LR (MC-LR) is considered to be the most dominant type of MCs present in Sri Lankan water bodies. Hence, there is a significant interest in water treatment strategies that ensures the removal of MCs, with the exploitation of microbes, which is considered to be a possible environmental friendly approach. Detection of MC-LR concentration and isolation of potential MC-LR degraders were carried out in 25 water bodies of Sri Lanka from $1^{\text {st }}$ September 2011 to $31^{\text {st }}$ August 2014. The highest MC-LR concentration was recorded from Girandurukotte reservoir as $158.9 \pm 4.71 \mu \mathrm{g} \mathrm{ml}^{-1}$. A total of 386 bacterial strains were isolated from all water bodies and out of them four isolates namely, Bacillus cereus (12GK), Stenotrophomonas maltophilia (4B4 and 1 JAY) and Rahnella aqautilis (13UL) have shown an overall metabolism of MC-LR. This is the first report of MC degrading R.aquatilis belonging to class gammaproteobacteria.
\end{abstract}

B.cereus, the most efficient MC-LR degrading bacterium showed $100 \%$ removal of MC-LR within eight days of incubation at $28^{\circ} \mathrm{C}$ where both S. maltophilia species and R.aqautilis showed $100 \%$ removal of MC-LR within 10 days of incubation. Highest metabolism of MC-LR by all four bacterial strains was shown at $32^{\circ} \mathrm{C}$. B.cereus showed $100 \%$ removal of MC-LR, at the end of 6 th day of incubation at $32^{\circ}$ C. S. maltophilia and $R$. aqautilis required 8 days to show $100 \%$ removal of MC-LR at $32^{\circ} \mathrm{C}$. MC-LR degradation efficiency of each bacterial strain was optimized at different concentrations 
of Phosphates $(0.005 \mathrm{ppm}$ to $0.05 \mathrm{ppm})$ and nitrates $(0.1 \mathrm{ppm}$ to $2.5 \mathrm{ppm})$. MC-LR degradation rate of $B$. cereus and $R$. aquatilis increased from $0.43 \pm 0.05 \mu \mathrm{g} \mathrm{day}^{-1}$ to 0.94 $\pm 0.15 \mu \mathrm{g}_{\text {day }}{ }^{-1}$ and from $0.38 \pm 0.01 \mu \mathrm{g} \mathrm{day}^{-1}$ to $0.56 \pm 0.17 \mu \mathrm{g} \mathrm{day}^{-1}$, respectively when phosphate concentration was increased from 0.005 to $0.01 \mathrm{ppm}$. Phosphate concentrations higher than $0.01 \mathrm{ppm}$ resulted a decrease in MC-LR degradation rate of B. cereus and R. aquatilis. S. maltophilia showed highest MC-LR degradation rate of $0.34 \pm 0.01 \mu \mathrm{g}$ day $^{-1}$ (4B4) and $0.38 \pm 0.002 \mu \mathrm{g}$ day $^{-1}$ (1 JAY) respectively when total phosphate concentration of the medium was increased up to $0.02 \mathrm{ppm}$ and higher levels of phosphate showed a decrease in degradation of MC-LR. A rapid degradation of MCLR was recorded by all four strains, with the increase of nitrate concentration in the medium from 0.1 to $0.4 \mathrm{ppm}$. MC-LR degradation rate for B.cereus increased from $1.76 \pm 0.05 \mu \mathrm{g}$ day $^{-1}$ to $3.98 \pm 0.15 \mu \mathrm{g}$ day $^{-1}$; In $S$. maltophilia, 4B4 and $1 \mathrm{JAY}$, MC-LR degradation rate increased from $1.98 \pm 0.17 \mu \mathrm{g}_{\text {day }}{ }^{-1}$ to $3.55 \pm 0.18 \mu \mathrm{g} \mathrm{day}^{-1}$ and from $1.78 \pm 0.03 \mu \mathrm{g}_{\text {day }}{ }^{-1}$ to $3.76 \pm 0.06 \mu \mathrm{g}_{\text {day }}{ }^{-1}$ respectively, where as in $R$. aquatilis MC-LR degradation rate increased from $1.86 \pm 0.05 \mu \mathrm{g}$ day $^{-1}$ to $3.55 \pm 0.11 \mu \mathrm{g}$ day $^{-1}$. Nitrate concentrations higher than $0.4 \mathrm{ppm}$ reduced MC-LR degradation rates of all strains Moreover, all four bacterial strains showed abilities to degrade other MC variants (MCLF, MCLW, MC-RR) and Nodularin (NOD). B. cereus acted as the predominant degrader of MC-LR and MC-LF showing a complete degradation of these toxin variants within eight and twelve days of incubation respectively. Both $S$.maltophilia strains (4B4 and 1JAY) showed a complete removal of MC- LR, MC-RR and MC - LF within 10,12 and 14 days of incubation accordingly. However, R. aquatilis showed a complete degradation only for MC- LR within 10 days of incubation. 
The molecular studies confirmed that all four bacterial strains harbor $m \operatorname{lr} A, m \operatorname{lr} B, m \operatorname{lr} C$ and $m \operatorname{lr} D$ genes in them. This confirms that these bacterial strains follow the traditional pathway of MC-LR degradation and break the toxic compound into non harmful products. Moreover, a sand filter was also developed incorporating the best degrader of MCs. Biofilm of the sand filter was developed by attaching bacteria into citric acid treated raw cotton. MC-LR elimination potential of sand filters was experimented using two full-scale sand filters: an experimental sand filter and a control sand filter. The control filter showed a $1 \%$ removal of MC-LR within three hours and $12 \%$ removal after four days. The experimental filter showed 3\% removal of MC-LR within three hour of incubation and $90 \%$ removal of by the end of four days. Therefore, present study has provided a potential solution to treat Microcystin contaminated water by exploiting environmental bacteria. 